\title{
Com o Pano em Mãos, Meu Nome é África: a Culminância da Experiência "Desfile de Turbantes"1
}

\author{
Con el Paño en Manos, Mi Nombre es África: la Culminación de la \\ Experiencia "Desfile de Turbantes"
}
With the Cloth in Hands, My Name is Africa: the Culmination of the Experience "Turban Parade"

\author{
Profa. Gilmara de Souza de Brito ${ }^{2}$
}

Prof. Dr. Marcos Antônio Bessa-Oliveira ${ }^{3}$

\begin{abstract}
Resumo
Este relato de experiência é o resultado de um projeto interdisciplinar que aconteceu no Colégio Militar de Campo Grande-MS, durante os meses de junho a setembro de 2017, envolvendo as disciplinas de Língua Portuguesa e História nas turmas de $8^{\circ}$ ano do ensino fundamental. O projeto buscou tratar do estudo das culturas africana e afro-brasileira e baseou-se em leituras, apresentações de vídeos, debates, discussões, tutoriais e oficinas sobre amarrações de turbantes, tendo em vista que o turbante dentro das culturas mencionadas foi utilizado como objeto de estudo durante toda a realização do projeto. No ano de 2017, o inicio e decorrer do projeto foi apresentado no "XXVII Congresso Nacional da Federação de Arte/Educadores do Brasil / V Congresso Internacional dos Arte/Educadores / II Seminário de Cultura e Educação de Mato Grosso do Sul "Enquanto esse velho trem atravessa..."” que foi realizado durante os dias 14 a 18 de novembro daquele ano, na Universidade Federal de Mato Grosso do Sul. Porém, como o projeto ainda estava em andamento, não foi possível apresentar a sua finalização. Desta forma, este relato de experiência vem apresentar a culminância e os resultados deste trabalho, nos quais alunos e professoras se envolveram em busca de transpor a visão deturpada que ainda encontramos em nossa sociedade em relação às culturas africana e afro-brasileira, bem como os significados da utilização dos turbantes por sujeitos destas e de outras tantas culturas pelo mundo a partir das perspectivas dos Estudos Culturais.
\end{abstract}

Palavras-Chave: Cultura Africana; Cultura Afro-Brasileira; Estudos Culturais; Interdisciplinaridade; Turbantes.

\footnotetext{
${ }^{1}$ Artigo apresentado no Simpósio Temático 12 - Relações Étnico-Raciais na América Latina: debates interseccionais na diáspora durante o II Seminário Latino-Americano de Estudos em Cultura - SEMLACult em Foz do Iguaçu/PR, Brasil, 2018.

2 Mestranda no PROFEDUC - Programa de Pós-Graduação Mestrado Profissional em Educação - pela Universidade Estadual de Mato Grosso do Sul. Possui graduação em História pela Universidade Federal de Mato Grosso do Sul/UFMS (2010). É membro do Grupo de Pesquisa NAV(r)E - Núcleo de Artes Visuais em (re)Verificações Epistemológicas - CNPq/UEMS. E-mail: profgilmarabrito@ hotmail.com.

${ }^{3}$ Doutor em Artes Visuais, área de concentração em Fundamentos Teóricos pelo IA/Unicamp. Professor DE/TI na Cadeira de Artes Visuais no Curso de Artes Cênicas e Professor Permanente do PROFEDUC na Universidade Estadual de Mato Grosso do Sul - UUCG. É Líder do Grupo de Pesquisa NAV(r)E - Núcleo de Artes Visuais em (re)Verificações Epistemológicas - CNPq/UEMS. Membro do NECC - Núcleo de Estudos Culturais Comparados - UFMS e do Núcleo de Pesquisa Estudos Visuais - UNICAMP. marcosbessa2001@ gmail.com.
} 


\begin{abstract}
Resumen
Esta experiencia en el informe es el resultado de un proyecto interdisciplinario que tuvo lugar en el Colegio Militar de Campo Grande-MS, durante los meses de junio a septiembre de 2017, con la participación de las disciplinas de Lengua Portuguesa e Historia en la clase de octavo grado de la escuela primaria. El proyecto buscó tratar el estudio de las culturas africana y afrobrasileña y se basó en lecturas, presentaciones de videos, debates, discusiones, tutores y talleres sobre atado de turbantes, teniendo en vista que el turbante dentro de las culturas mencionadas, fue utilizado como objeto de estudio durante toda la realización del proyecto. En el año 2017, el inicio y el transcurso del proyecto fue presentado en el "XXVII Congreso Nacional de la Federación de Arte / Educadores de Brasil / V Congreso Internacional de los Arte / Educadores / II Seminario de Cultura y Educación de Mato Grosso do Sul - "viejo tren atraviesa ..."” que fue realizado durante los días 14 a 18 de noviembre de ese año, en la Universidad Federal de Mato Grosso do Sul. Pero, como el proyecto aún estaba en marcha, no fue posible presentar su finalización. De esta forma, este relato de experiencia viene a presentar la culminación y los resultados de este trabajo, en los cuales alumnos y profesoras se involucraron en busca de transponer la visión distorsionada que aún encontramos en nuestra sociedad en relación a las culturas africana y afrobrasileña, así como los significados de la utilización de los turbantes por sujetos de éstas y de otras tantas culturas por el mundo a partir de las perspectivas de los Estudios Culturales
\end{abstract}

Palabras clave: Cultura Africana; Cultura Afrobrasileña; Estudios Culturales; Interdisciplinariedad; Turbantes.

\begin{abstract}
This experience report is the result of an interdisciplinary project that took place in the Military College of Campo Grande-MS, from June to September 2017, involving the Portuguese Language and History subjects in the 8th grade classes. The project sought to deal with the study of African and Afro-Brazilian cultures and was based on readings, video presentations, debates, discussions, tutorials and workshops on moorings of turbans, considering that the turban within the mentioned cultures was used as object throughout the project. In the year 2017, the beginning and the end of the project was presented at the XXVII National Congress of the Art Federation / Educators of Brazil / V International Art / Educators Congress / II Culture and Education Seminar of Mato Grosso do Sul - "While this old train runs ... "that was held during November 14 to 18 of that year, at the Federal University of Mato Grosso do Sul. However, as the project was still in progress, it was not possible to present its completion. In this way, this experience report presents the culmination and results of this work, in which students and teachers became involved in trying to transpose the misrepresented vision that we still find in our society in relation to the African and Afro-Brazilian cultures, as well as the meanings of the use of the turbans by subjects of these and of many other cultures by the world from the perspective of Cultural Studies.
\end{abstract}

Keywords: African Culture; Afro-Brazilian Culture; Cultural Studies; Interdisciplinarity; Turbans.

\title{
1. Introdução
}

O projeto interdisciplinar denominado "Com o Pano em Mãos, meu nome é África" surgiu a partir de conversas informais entre as professoras das disciplinas envolvidas, no caso, Língua Portuguesa e História, as quais discutiam sobre propostas que poderiam trabalhar juntas na tentativa de implementar atividades amparadas na Lei 10.639/2003, lei que inclui como norma o ensino da História e da Cultura Afro-Brasileira nas escolas.

No mesmo período em que o projeto acontecia no Colégio a professora da disciplina de História apresentou o relato das experiências vividas nas atividades no "XXVII Congresso Nacional da Federação de Arte/Educadores do Brasil / V Congresso Internacional dos Arte/Educadores / II Seminário de Cultura e Educação de Mato Grosso do Sul - "Enquanto esse velho trem atravessa...”; outros caminhos na experimentação e na formação docente em 
Arte" que aconteceu de 14 a 18 de novembro de 2017 na Universidade Federal de Mato Grosso do Sul.

Pelo fato de as atividades ainda estarem ocorrendo no período em que o texto foi submetido ao evento para apresentação, o trabalho mostrou apenas o início e o decorrer das atividades, tendo a sua finalização apresentada agora, neste trabalho. Assim, abordaremos de forma geral como foram as atividades realizadas, e teremos como foco a culminância do projeto que se finalizou com um desfile de turbantes em que os próprios alunos desfilaram e puderam escolher os tecidos, as cores e as amarrações de seus turbantes.

\section{Com o Pano em Mãos, Meu Nome é África!}

O projeto aconteceu entre os meses de junho a setembro de 2017, em que as professoras, em suas respectivas aulas, discutiram e debateram com os alunos assuntos sobre racismo, preconceito, discriminação e intolerância; amparadas nas apresentações de vídeos (curta-metragem "Vista Minha Pele" e tutoriais "Como fazer turbante, quais tecidos, medidas e onde comprar Preta Pariu" e "Como amarrar turbante rápido e fácil VEDA") e nas leituras ("Meu Avô Africano" e "Na Minha Pele") e produções de textos e cartazes (fig. 1), tutoriais sobre amarrações de turbantes e oficinas.

A culminância do projeto ocorreu com um desfile de turbantes no "Festival da Primavera", que foi realizado no mês de setembro daquele ano, em que os alunos, a partir dos conhecimentos adquiridos com as atividades realizadas em sala de aula, pesquisas, debates e etc., decidiram sobre as amarrações, cores e tecidos dos turbantes com os quais desfilaram, buscando a partir do referido desfile, as suas identificações com o turbante e os seus diversos significados, principalmente em relação às culturas africana e afro-brasileira que foram o foco de nosso projeto. 


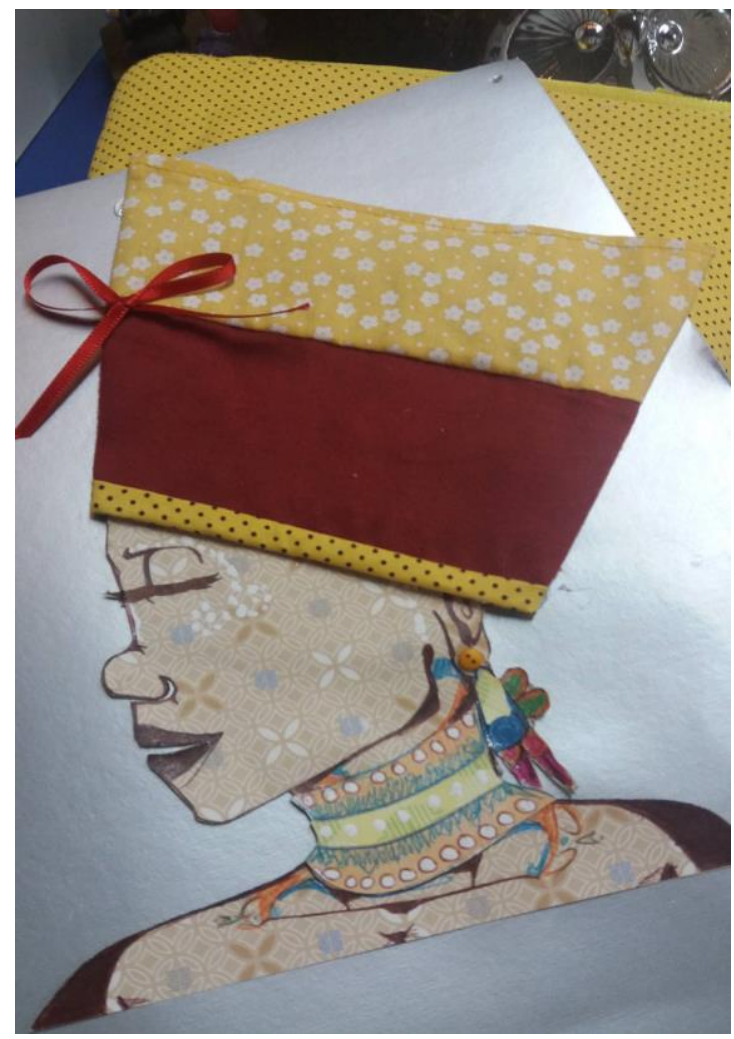

Figura 1 - Produção de Cartazes

Fonte: Arquivo Pessoal

Dentro das atividades realizadas neste projeto, tivemos como abordagem fundamental ou o "ponta pé” inicial para o seu desenvolvimento, o curta-metragem "Vista Minha Pele" (2003). O contexto do curta-metragem se dá em um cenário escolar, onde os personagens vivem situações invertidas da nossa realidade: os escravizados no Brasil foram os brancos, a discriminação e o racismo são voltados para os brancos e a maioria pobre da sociedade é branca. O cenário escolar é o do ensino privado e a protagonista do curta-metragem é a única branca da escola que sofre racismo por parte dos colegas. Ou seja, papéis invertidos de acordo com a realidade brasileira.

A intenção de trabalharmos com esse curta-metragem estava na perspectiva de despertarmos o sentimento de empatia nos alunos, para que eles refletissem sobre a questão da "inversão de papéis" dentro da sociedade, para se questionarem sobre o contexto em que vivemos baseado no preconceito, no racismo e na discriminação/exclusão racial. E a intenção das professoras ao pensarem sobre a possibilidade deste trabalho baseou-se na busca pela compreensão e reconhecimento por parte dos alunos de que são cidadãos brasileiros e herdeiros das raízes sócio-histórico-culturais formadas pelo indígena nativo, negro africano e branco europeu. 
Todo o trabalho que foi realizado em sala de aula pautou-se na busca pelo conhecimento e a reflexão sobre a nossa formação sócio-histórico-cultural em relação às nossas heranças advindas dos negros que compõem e que muito contribuíram para o nosso processo histórico, fazendo emergir o reconhecimento e a valorização das contribuições do negro em todo o processo de formação da nossa sociedade. Pois, a intenção maior que prevaleceu neste projeto foi transpor com a ideia errônea de que o negro aqui não produziu cultura, história e conhecimento, como se no passado foi apenas mão de obra para o trabalho escravo.

Para tanto, tomamos das perspectivas dos Estudos Culturais pensando no contexto em que "Os Estudos Culturais estão, assim, comprometidos com o estudo de todas as artes, crenças, instituições e práticas comunicativas de uma sociedade" (NELSON; TREICHER; GROSSBERG, 1995, p. 13). Sendo assim, a nossa proposta de trabalho deu-se na intenção de compreender as raízes culturais brasileiras em toda a sua formação, não negando de nossa cultura as matrizes de formação composta pelo nativo indígena, branco europeu e o negro africano; trabalhando para que nenhum desses povos fosse visto como melhor que outros, nossa proposta foi de uma perspectiva horizontal.

Como forma de ilustração para o nosso trabalho, decidimos por desenvolver um estudo mais profundo do turbante para a cultura africana e afro-brasileira. Desenvolvemos pesquisas através de tutoriais de amarrações de turbantes, estudamos as diversas cores e significados deles para essas culturas, assim como também estudamos as tantas outras formas de uso dos turbantes (religiosa, moda, gosto, cultural e etc. (fig. 2)), inclusive pelas diversas culturas espalhadas pelo mundo. 


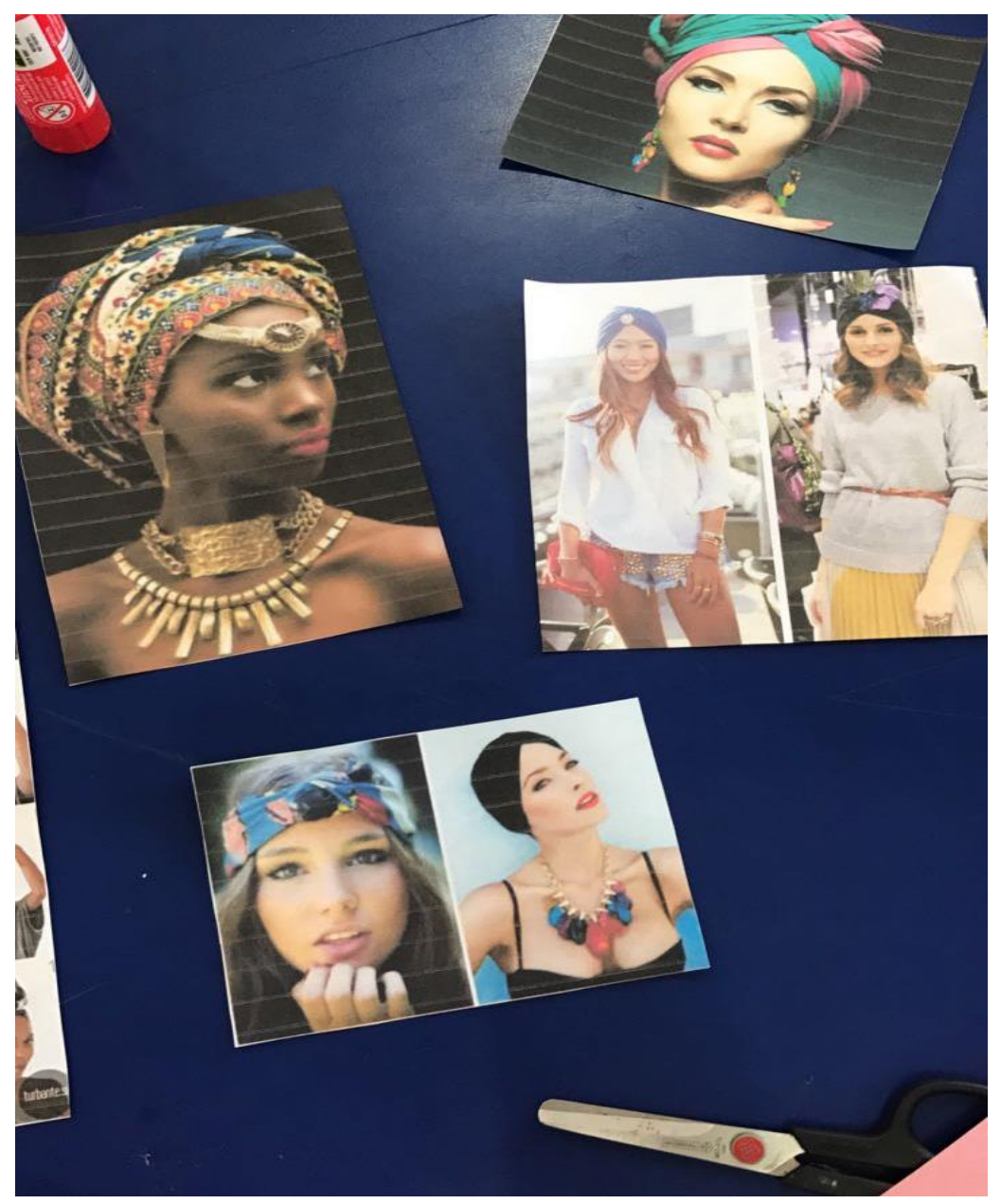

Figura 2 - Produção de Cartazes

Fonte: Arquivo Pessoal

A partir das atividades realizadas com estudos, pesquisas e etc., os alunos partiram para o "pano em mãos", momento em que "produziram" seus turbantes para o desfile final do projeto. Os próprios alunos amarraram, escolheram tecidos, cores e significados para os seus turbantes, foi o preparo para o desfile no "Festival da Primavera" do Colégio Militar de Campo Grande- MS (fig. 3), realizado no mês de setembro de 2017. 


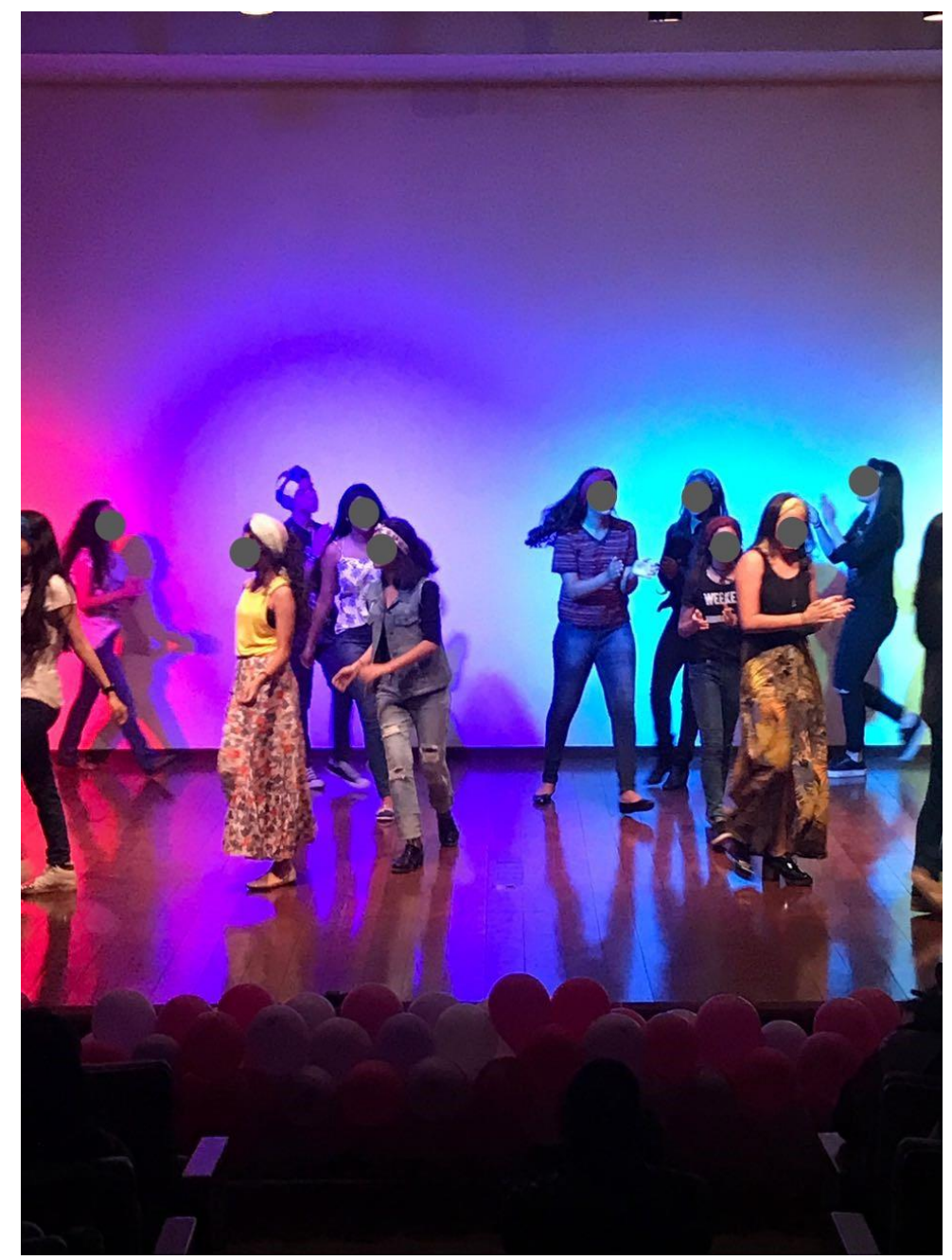

Figura 3 - Alunos Desfilando

Fonte: Arquivo Pessoal

Os alunos se envolveram das mais diversas formas. Era nítida a empolgação deles! E ainda assim, mesmo com toda a empolgação percebida da adolescência eufórica, conseguimos perceber neles a compreensão daquele tecido, a partir do momento em que deixa de ser um simples pano sobre a cabeça, tornando-se "sentido" para aquele que o utiliza.

Verificamos a empolgação dos alunos também a partir da escolha das roupas que usariam no desfile, das cores dos tecidos, dos modelos e amarrações dos turbantes; para as meninas, se deixariam ou não os cabelos para fora dos tecidos e etc. E, ainda, o que chamou muito a atenção das professoras foi que, a partir das atividades realizadas em sala de aula, alguns alunos passaram a ler, por vontade própria, dentro e fora da escola, leituras que abordam temáticas sobre o negro.

Um livro que foi muito comentado entre eles, sem que nós professoras tivéssemos indicado, foi a obra "Na Minha Pele" de autoria do escritor negro e ator global Lázaro Ramos, 
em que ele compartilha suas experiências pessoais como cidadão negro e chama o leitor para a reflexão sobre os temas relacionados ao racismo, preconceito e a discriminação racial.

Junto ao desfile os alunos ministraram uma oficina de turbantes para todos aqueles que quisessem aprender as amarrações e significados do adorno, dentro das perspectivas das culturas africana e afro-brasileira (detalhe na fig. 4).

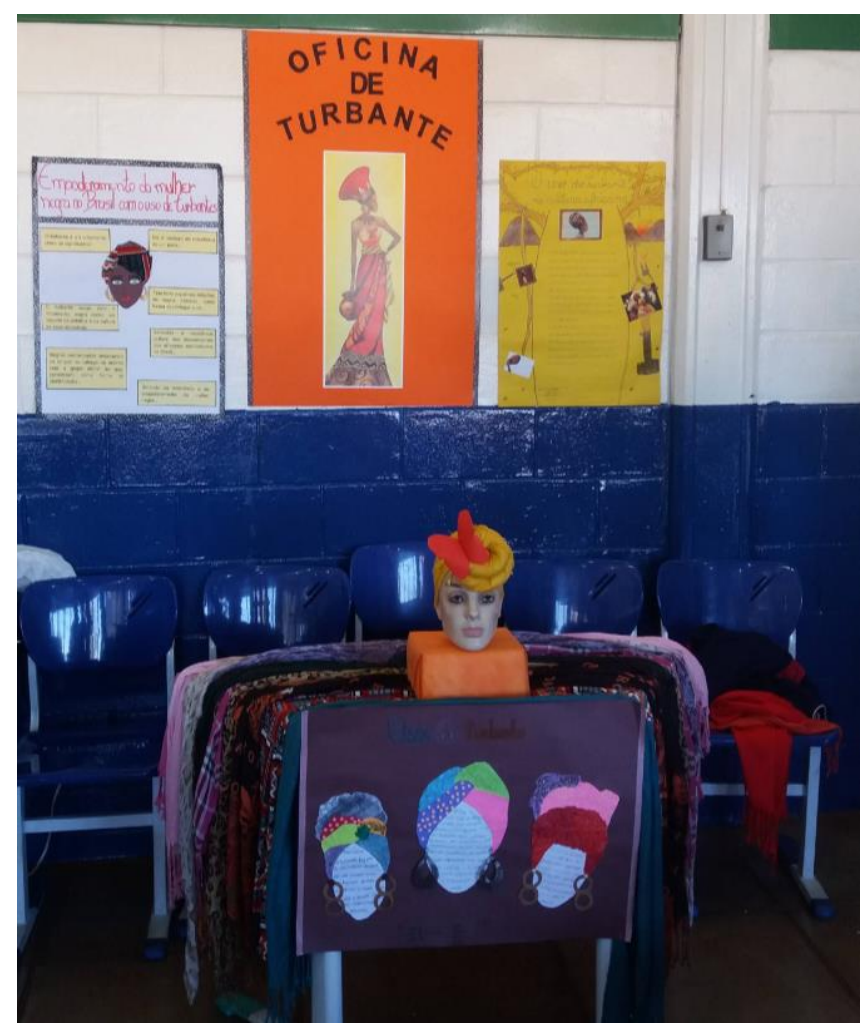

Figura 4 - Oficina de Amarração de Turbantes

Fonte: Arquivo Pessoal

A partir da atividade realizada tivemos muitas experiências, trocas de informações e valores, pois os alunos possuem acesso às tecnologias e muita curiosidade, e muitos deles saíram em pesquisas para trazer seus resultados nos debates realizados em sala de aula. $\mathrm{O}$ aprendizado foi mútuo entre alunos e professoras.

\section{Conclusões}

Como em qualquer prática escolar, levando em consideração que os sujeitos participantes são múltiplos, com suas diversas crenças, valores e pensamentos, podemos afirmar que se o objetivo foi o de levar os alunos à prática empática; conseguimos perceber que, em algum grau este objetivo foi alcançado. Não conseguimos determinar em que grau, 
em quantos alunos, mas que no geral, reflexões surgiram e questionamentos foram levantados.

E são essas reflexões e questionamentos que levarão os diversos sujeitos (alunos, professores e funcionários da escola) à (re)pensarem sobre os sujeitos sociais brasileiros e as diversas culturas existentes no mundo, através da autonomia, auto-estima, reconhecimento, respeito e valorização da sua cultura e da cultura do outro.

\section{Referências}

BRASIL. Lei $N^{o} 10.639$, de 9 de janeiro de 2003. Altera a Lei no 9.394, de 20 de dezembro de 1996, que estabelece as diretrizes e bases da educação nacional, para incluir no currículo oficial da Rede de Ensino a obrigatoriedade da temática "História e Cultura Afro-Brasileira",

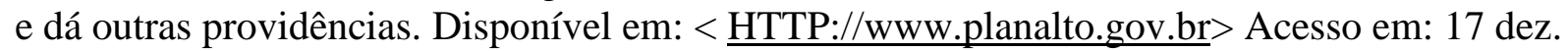
2018.

CAMPOS, Carmen Lucia. Meu avô africano. Panda Books, 2011.

NELSON, Cary; TREICHLER, Paula A.; GROSSBERG, Lawerence. "Estudos culturais: uma introdução”. In: SILVA, Tomaz Tadeu da. (Org.). Alienígenas na sala de aula: uma introdução aos estudos culturais em educação. Petrópolis, RJ: Vozes, 1995 - (Coleção estudos culturais em educação). P. 7-38.

PRETA PARIU. Como amarrar turbante rápido e fácil. 2016. Disponível em: < https://www.youtube.com/watch?v=D6SAOk8Ba8U>. Acesso em: 17 dez. 2018.

PRETA PARIU. Como fazer turbante, quais tecidos, medidas e onde comprar. 2017.

Disponível em: < https://www.youtube.com/watch?v=8QVNAu8-hbo >. Acesso em: 17 dez. 2018.

RAMOS, Lázaro. Na minha pele. 1ª ed. Rio de Janeiro : Objetiva, 2017.

VISTA MINHA PELE. Curta Metragem. Direção: Joel Zito Araújo, Produção: CEERT Centro de Estudos e Relações de Trabalho e Desigualdades. Brasil, 2003. 